\title{
Natural endogenous factors of geoecological transformation of the mountain part of North Ossetia
}

\author{
Khyisa Chotchaev ${ }^{1}$, Vladislav Zaalishvili ${ }^{1, *}$, and Boris Dzeranov ${ }^{1}$ \\ ${ }^{1}$ Geophysical Institute, Vladikavkaz Scientific Center, Russian Academy of Sciences, Markova Str., \\ 93a, Vladikavkaz, 362002, Russian Federation
}

\begin{abstract}
Geoecological transformation of the biocenosis habitat is an evolutionary process, predetermined by the interaction of the lithosphere with the hydrosphere, atmosphere and the solar system as a whole, under the condition of anthropogenic impact absence. Geoecological transformation occurs under the influence of many natural factors of an endogenous and exogenous nature, the effects of which in the mountainous areas are especially intensive and damageable, due to the sharp and intense exposure forms of exogenous factors of the erosive destruction, the presence of a large gravitational potential for a spatial removal of the destroyed material, poor protection of the bedrocks by biogeocenosis, low strength of terrigenous rocks, etc. The main factors of the intensive geoecological transformation of the mountain landscape are endogenous geodynamic processes. The Greater Caucasus, as the geosynclinal region of young Alpine orogenesis, is characterized by the active deep geodynamics, the focal zones of which can be activated in time and migrate in the lithosphere, as evidenced by the interchange of the periods of seismic activity and relative passivity of deep geodynamic processes (fault tectonics, seismicity and magmatic manifestations). A high density of the tectonic faults contributes to the weakening of rock strength in the zone of a faulting crop out due to jointing and claying along the friction planes.
\end{abstract}

\section{Introduction}

Highlands are ecologically vulnerable territories; the dynamics of their changes depends on many geological, geographical and climatic factors. Rugged steep slopes, temperature differences, incompetent lithology of covering deposits under a thin vegetation layer as well as heavy rainfall in a sharply changing climate (characterized by pronounced vertical zonality from temperate continental in the lower part of the valley to nival at altitudes of more than $3000 \mathrm{~m}$ ) - all of that easily turned even animal paths and favorite pet routes on summer pastures into channels and cavin, which subsequently progress to the landslide slopes and mudflows. The scenario of geoecological transformation of highlands caused

\footnotetext{
* Corresponding author: vzaal@mail.ru
} 
only by the erosion, mainly by climatic impact on the geological environment, without taking into account the geodynamic or technogenic components, is certainly long, but a generation of contemporaries of the initial stage of landscape transformation can become an eyewitness to its profound changes, when the initial area, classified as 2 nd or 3rd category for agricultural purposes, suitable mainly for hayfields and pastures, are changed into the land of 5th and 6th categories, hardly suitable and unsuitable for use as agricultural land.

Physical phenomena in the zone of alpine tectonomagmatic activation of the Greater Caucasus are characterized by complex engineering and geological conditions characteristic of mountain folded regions, caused by a variety of lithological composition of rocks, their intense tectonic disturbance, active neotectonics and seismicity, a variety of geomorphological forms and the wide development of modern exogenous geological processes, among which the most common are weathering, slope wash and deluvial accumulation, erosion and mudflow, gravity (landslide, landslide, avalanche) and karst processes.

Weathering is the most common geological process. In the highlands (above $2000 \mathrm{~m}$ ), the leading role is played by a frost weathering, which leads to the formation of microcracks in the rock and its mechanical destruction in future. This belt is characterized by the absence of soil and vegetation cover, the widespread development of glacial, fluvioglacial and landslide- colluvial deposits.

In the mountain-forest zone, the weathering effect is less pronounced due to the bedrock protection by soils and a root system of vegetation, which led to the local character of slope gravity processes in such landscapes.

In the midlands and lowlands, the role of chemical and bacteriological weathering is increasing. Shales of the lias and rocks of the flysch formation are weathered especially intensively. During physical weathering, mudstones and marls under the influence of alternating drying and moistening lose their solidity, disintegrating to wood and small gravel. Sandstones, siltstones and limestones break up into separate blocks and pieces.

Any exogenous process associated with the interaction of the lithosphere with the atmosphere leads to a more or less geoecological transformation and, ultimately, is an evolutionary transformation of the Earth. This process can be slowed down or accelerated depending on the degree of influence of such factors as geodynamic activity or anthropogenic impact [1]. Geoecological transformation in an evolutionary mode naturally transforms a regional biocenosis without any special consequences for it, while a revolutionary transformation under the influence of endogenous or technogenic processes turns into a catastrophe for some or many species.

As a rule, mountainous areas are assigned a status of intensive development due to the mineral resources in the bowels, which predetermines intensive technogenic interference in geoecology. On the other hand, mining territories owe their stores to the endogenous geodynamic activity. The main fund of shallow ore deposits is concentrated in geosynclinal areas, such as the Caucasian orogen.

The Greater Caucasus, as the geosynclinal region of young Alpine orogenesis, is characterized by active deep geodynamics, the focal zones of which can be activated in time and migrate in the lithosphere, as evidenced by the interchange of seismic activity periods and relative passivity of deep geodynamic processes (fault tectonics, seismicity and magmatic manifestations).

The current period of the Greater Caucasus state should be attributed to the period of increased geodynamic activity, which is associated with stresses on its southern borders caused by the Arabian plate.

A complex of unfavorable natural factors of endogenous and exogenous nature, which periodically occurs in the territory of the mountainous part of the Central Caucasus, allows us to classify confidently the territory as a seismic hazardous area of 7-10 point intensity. 
At the same time, the entire mountainous part is assigned to a 9-10 point intensity according to the classification of maps of general seismic zoning at a scale of 1: 8000000 (GSZ-97).

High seismicity caused by the active deep geodynamic processes and stresses in the zone of interaction of block structures affects a strongly dissected relief, activating many dangerous exogenous processes (mudflows, landslides, avalanches, landslides) [2].

Technogenic component of the geoecological transformation of the territory of the ore province of the mountainous part of North Ossetia has a history of about 200 years, when the extraction of lead-zinc ore began with a makeshift method at many of the mine workings in the region.

Industrial development sharply increased the technological impact on the environment, due to the increase in prospecting and exploration, road construction, commissioning of new mines and other large engineering structures, which negatively affected the geoecological situation of the territory.

The attempt to assess the influence of endogenous geodynamic activity of a seismotectonic and post-volcanic nature on the geoecological transformation of an intensive development area is considered in the article.

\section{The deformation effect of physical fields on rocks}

Physical and chemical basis of intermolecular bonds in rocks are simultaneously the precursors of the occurring disturbances of these bonds, the cause of which is an increase in stresses in the rocks and subsequent elastic or residual deformations. Based on the fundamentals of intermolecular bonds, it is obvious that electromagnetic fields are the indicator, since deformations of the crystal lattice cause a change in the distances between atoms and quantum-mechanical fluctuations in the electron density of particles (molecules, atoms). Instantaneous distribution of the electric charge of the molecule, which corresponds to the instantaneous dipole moment of the molecule (or a higher order multipole moment), inducing an electric multipole moment in another molecule. The avalanche effect of instantaneous multipole moments creates the dispersive interaction energy, which manifests in the form of electromagnetic pulses (EMP) of the E-dispersive field.

The stage of destruction is preceded by the occurrence of dislocations, i.e. local displacements of individual atoms of the crystal lattice. The dislocation can propagate in the crystal due to the less additional external energy than is required for the defect formation with a perfect lattice.

The most high-frequency part of the EMP spectrum corresponds to the occurrence of such dislocations, many of which lead to the formation of fracture zones and tectonic disturbances [3]. Each rank of tectonic manifestation is accompanied by a certain spectrum of electromagnetic pulses, while low-frequency pulses are characteristic of violations of the relatively low orders and vice versa. Undoubtedly, the above mentioned applies to any single complex, whether magmatic, metamorphic or sedimentary, with the only difference being that the strain spectra of each complex will be individual.

Since the electromagnetic pulse is a vector, and its amplitude-frequency characteristics and spatial orientation are the most important parameters for determining the impact nature, it is advisable to measure EMP in the recording mode of 3 components. In combination with the geotechnical, lithological, and structural-tectonic conditions of the field, the data of 3 component observations of electromagnetic pulses make it possible to define the intervals of the developed array with an active dynamics of the development of mechanical stresses, as well as give a qualitative characteristic of the deforming factor and make a forecast for the development of dangerous processes. 
The use of the EMP method in the solution of the problems of detecting, monitoring the development of the event in the form of intense deformation of the environment, preventing catastrophic consequences and forecasting such large geodynamic events as rock bumps at pits and mines at great depths, as well as earthquakes, seems to be promising for ensuring the safety of underground mining operations.

Plastic deformations associated with the appearance and development of defects at the level of structural and texture features of the material in the form of micro- and macrocracks and allotropic changes in the crystal lattice are manifested in the form of separate acoustic pulses, which serve as a universal sign of detection of multi-scale cracks in the frequency spectrum of emission. Such pulses appear in the crystal lattice even in the elastic region, and arise due to the fact that the medium is inhomogeneous at the level of texture-structural packing, is loaded unevenly and plastic deformation occurs in some regions, although in general, the process remains elastic.

At seismic or tectonic pressures on the rock, the process from the beginning of loading to a complete fracture will be marked by characteristic differentiated amplitude-frequency spectra reflecting the deformation stages at the levels of the crystal lattice, structural-texture and lithological structure of the medium [4].

At the pressures exceeding the rock ultimate strength, the phase of elastic strains is replaced by nonlinear changes in the structure of the medium (plastic strains) and discontinuities. Next, a rock collapse or a discharge in the form of a rock bump follows.

Movements at the intermolecular level of the structural and tectonic packing of the rock generate high-frequency elastic longitudinal and transverse waves, the frequency spectrum of which will shift to the left while the preparation, appearance and development of residual deformation occur. The frequency range at the early stage of the development of the stressstrain process can be recorded by microwave sensors, the introduction of which will allow getting a complete cycle of preparation, development and progress of the stress-strain processes in hazardous areas of mine workings. The stress, corresponding to the initial stage of deformation in the form of a microcrack, will have a short duration (of the order of microseconds or fractions of microseconds) [5].

Longitudinal-shear displacements with increasing pressure are no longer elastic; elastic deformation passes into plastic and the part of the energy starts to go to the dissipative losses, including residual deformation, which is used in practice of polarization-optical registration of stresses experienced by a rock mass and determined by the ratio of the main optical axes, for which optical composite materials are used [6].

The rock represents a mineral association, each of which is packed in a certain syngony set of chemical elements. They in turn, are synthesized by crystals with a specific crystal lattice, with different forces of interatomic bonds. Under the stresses exceeding any forces of interatomic bonds, including rocks brought to the surface, a dislocation arises in the rock, mineral or crystal. This dislocation is a site of breakdown under the influence of physical, chemical, biological weathering or erosion factors. Stresses that can disrupt the forces of intermolecular or interatomic bonds arise in the lithosphere during seismotectonic impacts. Moreover, if the tectonic impact is primary as an event and is the main in terms of the destructive force, then the seismic impact is secondary and the stresses generated by it do not exceed hundredth and thousandth parts of the properly tectonic stresses. However, the destructive effectiveness of a seismic impact on the exposed, weakened by the fracturing and stratification bedrock significantly exceeds the one, due to the vibrational impact of different frequency. Though, such a statement for a region like the described one, with active neotectonics, dense tectonic irregularity by regional deep and interblock faults of the higher order, is very arbitrary, since many exogenous geological processes (EGP) known in the region are somehow controlled by the river network basins, formed due to the tectonic disturbances (Ardon, Terek, Genaldon, Urukh) [7]. 
The largest development of EGP occurs in the mountainous and foothill parts of the Caucasus, where a steady long-term tendency of the increase in regional activity of their manifestation, caused by the growth in the relief energy as a result of the modern tectonic movements and the influence of anthropogenic impact $[8,9]$.

Almost all known types of erosion processes, including dips in the mine workings, which manifest as the consequences of the mining industry, are characteristic of the territory under consideration.

High seismic activity, intense tectonic fragmentation, dissected alpine topography, and a dense hydrographic pattern should be considered the main negative natural factors that determine the origin mechanisms of the genetic types of exogenous geological processes that are characteristic for the region. Seismicity disturbs the stability of soils and poorly cemented fractured bedrock, a dissected relief contributes to gravity creep. The dense hydrographic pattern serves as a storage and subsequent overpass when the accumulated stormwater or meltwater of glaciers acts as a mover.

To take into account the influence of the deep geodynamic factor on the occurrence and running of exogenous geological processes (EGP), the tectonic activity of seismic generating zones along deep faults and geosutures is generalized by such parameters as the speed of vertical movements, heat flux density, and the number of strong earthquakes [10]. In the process of research for prediction the development of dangerous geological processes based on an analysis of endogenous regime-forming factors, it was established that endogenous and exogenous abnormal phenomena gravitate toward periods of increased solar activity.

The maximums of solar activity are a powerful destabilizing factor for the geological environment, geophysical fields, atmosphere and biosphere of the Earth. It leads to a violation of thermal equilibrium in the atmosphere, which, in turn, causes macroturbulent exchange.

The stability of 11-year cycles of solar activity is unusually high and extends to many components of the earth's crust. The humidification and air temperature extremums within the period of the secular solar cycle are confined to both the minima and maxima of the 11year solar cycle.

The periods of maximum increases in landslide areas also coincide with increases in solar activity and with the largest number of earthquakes within the estimated (conditionally) radius of manifestation of anomalous effects that correlate with the maximum magnitudes of these earthquakes.

Given the role of the endogenous factor in the activation of landslide processes in the North Caucasus, a long-term prognosis is made on the basis of a seismic zoning scheme, where five levels of the risk of EGP are distinguished by the degree of expected seismic impact: negligible hazardous (IEGP/KS), slightly hazardous (IIEGP/KS), moderately hazardous (IIIEGP/KS), very hazardous (IVEGP/KS) and extremely hazardous (VEGP/KS). The mountainous territories of the Republic of North Ossetia-Alania belong to the IVEGP/KS level, which is very hazardous.

To prognosticate the development of EGP, taking into account modern neotectonics and intra-platform deformations of the Caucasus, due to the collision of the Arabian Plate and the Eurasian Plate, identification is carried out depending on the geodynamic activity of the Caucasus.

The spatial confinement of gravitational processes to blocks of high and very high geodynamic activity, controlled by large fault zones of the Caucasian direction and regional deep faults of the meridional direction was established.

In the central part of the Greater Caucasus, EGP activation in the intersection areas of large tectonic suture zones of sub-latitudinal direction with lower-order meridional faults was recorded. In addition to other causes of landslide processes, in the central part of the 
Caucasus there is a widespread development of lateral erosion due to the action of floods that periodically arise as a result of intense melting of glaciers.

The sad fact of geoecological transformation is the paroxysmal outburst of the Kolka glacier with a tragic death of 114 people. Overnight, the flowering valley of the river Genaldon for $21 \mathrm{~km}$ turned into a lunar landscape with a corresponding consequence for the local biocenosis.

It has been established that the valley of the Kolka glacier is cut longitudinally by the Syrkhubarzond fault, which is the northern limit of the relict scar (suture) and the continuation of the main Caucasian thrust to the east. The fault is supposedly associated with the chamber of the extinct Kazbek stratovolcano and continues to serve as a channel for unloading post-volcanic gases and fluids of the cooling massif.

\section{Quaternary formations as a potential resource of EGP}

Intensive tectonic fragmentation and active seismicity in the complex impact of exogenous and climatic factors predetermined the accumulation of Quaternary sediments of various genesis, concentrated both in the valleys of river networks and in the lowlands of the slopes which are potential masses of EGPs of various types.

The data on the Quaternary formations of the Pleistocene-Holocene century (Q1-IV), concentrated on the slopes of the most developed river valleys with a pronounced tectonic heritage are given below.

Traces of Terek glaciations in the valley of the river Ardon are reflected mainly in landforms. At an altitude of 300-400 m above the modern riverbed, the gently sloping and wide bottom of the ancient valley is clearly expressed. It can be traced from the village Staryi Biz up the river Ardon to the village Nuzal. On the surface of this bottom and in a number of other places there are accumulations of boulders and pebbles of weathered granites and other crystalline rocks, which are the remains of Terek (Riss) moraines.

This period is characterized by glacial deluvial, colluvial and landfall-landslide formations in the mountainous regions of the territory and subaerial cover sediments within the Vladikavkaz basin.

Moraines of the Late Pleistocene-Holocene time are relatively widespread in the upper reaches of such rivers as Lakhumedon, Ursdon, Urukh, Fiagdon, Tsariitdon, Armkhi, Kistinka. They are composed of blocks, boulders and rubble from the surrounding bedrock. The thickness of glacial deposits is from 10 to $50 \mathrm{~m}$.

Deluvial and colluvial deposits are most widespread in the mountainous part especially along the Skalistyi Ridge scarp. They often continuously cover the gently sloping near the water-divide sections of the slopes and form loops at their foot. Deluvium is represented by loam, sandy loam and fine gravel and separate larger fragments. The thickness of the deluvial deposits ranges from $0.2-0.5 \mathrm{~m}$ to $2-4 \mathrm{~m}$.

Landfall-landslide formations are distributed mainly along the scarp of the Skalistyi Ridge. They are represented by strongly fractured, crushed blocks and products of the destruction of this structure (lime rubbly loams). The area of these formations ranges from 1 to $3.5 \mathrm{~km} 2$. Power ranges from the first meters to $50 \mathrm{~m}$.

Formation of structural landslides on the southern slope of the Skalistyi Ridge N.L. Enna (1988) associates with the outcrops of the Middle Jurassic shales, along which blocks of Upper Jurassic limestone slid down. The landslide blocks of the Upper Jurassic rocks are composed of large boulders and blocks of intensely fractured limestones, measuring up to 1.5-2.0 km in length and with a thickness from 10 to $575 \mathrm{~m}$, retaining their original structure. In the upper reaches, in places of their separation, cirque-like depressions are observed. 
Holocene sediments are represented by a number of genetic types of Quaternary sediments.

These are alluvial, deluvial, proluvial, colluvial (collapse and creep), fluvioglacial, glacial deposits and identified as a separate genetic type - ice. In addition, there are lacustrine and technogenic types of deposits in nature, which are not reflected on the maps due to their small size.

Alluvial deposits of floodplains of the I and II floodplain terraces occur in all valleys, except for breakthrough areas in mountainous areas. Alluvium is composed of boulderpebble-gravel material with small lenses of sand and loam. In mountainous areas, alluvium material is relatively larger compared to the flat part of the territory. Their granulometric composition varies within: boulders - 41-26\%; pebbles - 41-52\%; sand - 17-28\%, silty clay and silty particles - 9-11\%.

Petrographic composition: igneous rocks (granites, andesites, diabases) - 51-76\%; metamorphic rocks (crystalline shales, quartzites) - 20-10\%; sedimentary rocks (limestones, dolomites, shales) - 22-1\%.

The thickness of the channel alluvium in the foothill part is up to $55 \mathrm{~m}$, in the mountain part up to $10-15 \mathrm{~m}$. The thickness of the alluvium of terraces is not more than $5 \mathrm{~m}$.

The Holocene is characterized by the last retreat stages of the 2nd Bezengi glaciation, the historical stage of glaciation (2.5-2 thousand years ago) and the last glaciation of the XVII-XIX centuries. The stages of glaciation are traced by end moraine shafts in the troughs in different parts of the highland zone. Moraines of the early stages of glaciation are deeply buried at the bottom of the troughs, under late and postglacial accumulations. The early stage moraines, dating to the mid-19th century, sometimes in 1-2.5 km from the modern edge of the glaciers, do not indicate a halt, but some general expansion of Caucasian glaciation in this era, followed by significant degradation of glaciers over the last century.

Currently, there are 227 glaciers in the territory of Mountain Ossetia with a total area of glaciation of $170 \mathrm{~km} 2$. On a geological map of the USSR on a scale of 1: 1000000 (1986), glaciers are highlighted as a separate genetic type of Quaternary formations.

In the alpine zone below the moraines in the river valleys, fluvioglacial deposits occur, which are usually overlapped by colluvial and deluvial formations covering the slopes of the ranges.

The lithological composition of moraines and fluvioglacial deposits is very diverse and it is directly dependent on the rocks that make up the sides and bottom of the glacial valleys. They are composed of boulders, pebbles, gravel, sand and loam.

Proluvial accumulations form an outflow cone in the estuarine parts of small streams and temporary streams and consist of poorly sorted clastic material - sand, gravel and small blocks mixed with silty-clay material.

Colluvium creeping is noted everywhere along the scarp of the Skalistyi Ridge. Landslides are compounded by rubble and small blocks cemented by loam. Most of them are in an active stage of development. The power of landslide formations sometimes reaches $100-120 \mathrm{~m}$.

Structural landslides of Upper Jurassic fractured limestones, with preserved lengths of up to $1.25 \mathrm{~km}$, are developed near the Skalistyi Ridge.

\section{Conclusion}

The largest development of EGP occurs in the mountain and foothill parts of the Caucasus, where there is a steady long-term trend of increasing regional activity of their manifestation, due to an increase in the relief energy as a result of modern tectonic movements and the influence of anthropogenic impact. 
The main negative natural factors that determine the emergence mechanisms of genetic types of exogenous geological processes that are characteristic for the region should be considered high seismic activity, intense tectonic fragmentation, dissected alpine topography, and a dense hydrographic pattern. Seismicity disturbs the stability of fractured bedrock, dissected relief promotes gravitational sliding, and a dense hydrographic pattern serves as a storage and subsequent overpass when accumulated storm rain water or glacier melt acts as a mover.

In the central part of the Greater Caucasus, the activation of dangerous geological processes was recorded in the intersection zones of large tectonic suture zones of sublatitudinal direction with lower-order meridional faults.

In the process of research to prognosticate the development of dangerous geological processes based on an analysis of endogenous regime-forming factors, it was established that endogenous and exogenous abnormal phenomena gravitate toward periods of increased solar activity.

\section{References}

1. I. Kopylov, Researches in the field of natural sciences 6, 35-43 (2015)

2. V. Osipov, G. Postoev, A. Kazeev, Geoecology 2, 119-133 (2015)

3. Hk. Chotchaev, A. Kolesnikova, M. Maysuradze, V. Shepelev, Geology and geophysics of Russian South 4, 179-190 (2018)

4. O. Popova, A. Zhigalin, M. Popov, F. Arakelyan, V. Nedyadko, Geoecology 2, 155-169 (2014)

5. Hk. Chotchaev, Geology and Geophysics of Russian South 3, 129-140 (2016)

6. A. Kolesnikova, Hk. Chotchaev, A. Dzhgamadze, Proceedings of the IV International Scientific and Practical Conference dedicated to the 65th anniversary of V.B. Zaalishvili, 303306 (2014)

7. A. Viktorov, Geoecology 2, 146-155 (2014)

8. A. Dorozhko, V. Makeev, G. Batrak, I. Pozdnyakova, Geoecolog, 2, 133-147 (2015)

9. G. Kocharyan, Geoecology 6, 483-497 (2012)

10. G. Turikeshev, B. Kochurov, Problems of regional ecology 6, 78-83 (2014) 